\title{
Sarkosyl defines three intermediate steps in transcription initiation by RNA polymerase III: application to stimulation of transcription by E1A
}

\author{
Robert Kovelman and Robert G. Roeder \\ Laboratory of Biochemistry and Molecular Biology, The Rockefeller University New York, New York 10021-6399 USA
}

\begin{abstract}
We used Sarkosyl to analyze steps along the pathway of transcription initiation by RNA polymerase III. Sarkosyl $(0.015 \%)$ inhibited transcription when present prior to incubation of RNA polymerase III, TFIIIB, and TFIIIC with the $\mathrm{VA}_{\mathbf{I}}$ gene, whereas it had no detectable effect on initiation or reinitiation of transcription when added subsequently. The formation of the corresponding $0.015 \%$ Sarkosyl-resistant complex required the presence of TFIIIC, TFIIIB, and RNA polymerase III but not nucleoside triphosphates. The addition of $0.05 \%$ Sarkosyl after this early step selectively inhibited a later step in the preinitiation pathway, allowing a single round of transcription after nucleoside triphosphate addition but blocking subsequent rounds of initiation. This step occurred prior to initiation because nucleoside triphosphates were not required for the formation of the corresponding $\mathbf{0 . 0 5} \%$ Sarkosyl-resistant complex. These observations provided a means to distinguish effects of regulatory factors on different steps in promoter activation and function. Using $0.05 \%$ Sarkosyl to limit reinitiation, we determined that the E1A-mediated stimulation of transcription by RNA polymerase III resulted from an increase in the number of active transcription complexes.
\end{abstract}

[Key Words: RNA polymerase III; transcription complex; adenovirus; E1A; Sarkosyl; VA I gene]

Received September 12, 1989; revised version accepted January 23, 1990.

The transcription of eukaryotic genes requires auxiliary factors in addition to one of the three eukaryotic RNA polymerases ( $\mathrm{Ng}$ et al. 1979; Weil et al. 1979; Grummt 1981). In the case of genes transcribed by RNA polymerase III, two commonly-required factors, TFIIIB and TFIIIC, are necessary and sufficient for the transcription of tRNA and VA RNA genes (Segall et al. 1980; Shastry et al. 1982), whereas $5 S$ gene transcription requires, in addition, the gene-specific factor TFIIIA (Engelke et al. 1980). Preinitiation complexes containing these factors are assembled on the internal promoters in a defined order (Lassar et al. 1983; Setzer and Brown 1985; Bieker et al. 1985): For VA and tRNA genes this is TFIIIC, then TFIIIB, and, finally, RNA polymerase III. On the VA and some tRNA genes, TFIIIC is sufficient for formation of a highly stable complex, while other tRNA genes require stabilization of TFIIIC binding by TFIIIB for stable complex formation (Lassar et al. 1983; Baker and Hall 1984; Fuhrman et al. 1984). In the case of the 5S gene, these interactions are preceded by the formation of a metastable 5S promoter-TFIIIA complex (Engelke et al. 1980; Lassar et al. 1983). In all cases the stable preinitiation complexes support multiple rounds of transcription and remain refractory to challenge by competing templates (Bogenhagen et al. 1982; Lassar et al. 1983; Fuhrman et al. 1984).
The steps and factors involved in the formation of a transcription complex are understood at various levels of detail. TFIIIA from Xenopus laevis has been purified to homogeneity (Engelke et al. 1980) and cloned (Ginsberg et al. 1984), and its interactions with the $5 \mathrm{~S}$ promoter have been studied in detail (for review, see Geiduschek and Tocchini-Valentini 1988). On the other hand, although the promoter elements for VA and tRNA genes were analyzed in detail some time ago (for review, see Ciliberto et al. 1983), TFIIIB and TFIIIC from different organisms (i.e., yeast and human) have only recently been purified /e.g., see Klekamp and Weil 1986a; Waldschmidt et al. 1988; Cromlish and Roeder 1989; Yoshinaga et al. 1989). Consequently, there is correspondingly less information about the structure, mechanism of action, and regulation by other factors. This contrasts with our present understanding of prokaryotic RNA polymerase initiation mechanisms and regulatory factor interactions (for review, see McClure 1985).

Studies with selective transcription initiation inhibitors in relatively crude systems have defined distinct steps that can be analyzed further as purified components become available. Thus, in the case of specific initiation by RNA polymerase II, Hawley and Roeder (1985, 1987) showed that there are at least two steps in the overall pathway that are differentially sensitive to the 
anionic detergent Sarkosyl and that may correspond to steps defined by studies with more purified factors (Van Dyke et al. 1988; Buratowski et al. 1989). Sarkosyl has also been shown to affect transcription by RNA polymerase I (Kato et al. 1986) and RNA polymerase III (Klekamp and Weil 1986b), although its effects on individual steps in complex formation in the class III system have not been examined previously.

In this report, we show that different concentrations of Sarkosyl inhibit the formation of two distinct preinitiation complexes on the $\mathrm{VA}_{\mathrm{I}}$ gene and that Sarkosyl can be used to limit reinitiation and therefore to assay single rounds of transcription. This has allowed us to show that the E1A-mediated stimulation of $\mathrm{VA}_{\mathrm{I}}$ transcription, previously demonstrated to be mediated by an increase in the level of a transcriptionally more active form of TFIIIC (Hoeffler et al. 1988), results from an increased number of functional transcription complexes.

\section{Results}

0.015\% Sarkosyl inhibits preinitiation complex formation

To determine whether any steps prior to transcription initiation by RNA polymerase III were differentially sensitive to inhibition by Sarkosyl, we employed the two-step assay protocol shown in Figure 1A. In step 1 , the plasmid containing the adenovirus $V_{A}$ RNA gene $\left(\mathrm{pVA}_{\mathrm{I}}\right)$ was preincubated with phosphocellulose fractions containing TFIIIB, TFIIIC, and RNA polymerase III. In step 2, transcription was started by the addition of NTPs. Sarkosyl was added to various final concentrations (as noted above the lanes in Fig. 1A) either before the addition of the factors to the $\mathrm{VA}_{\mathrm{I}}$ template in step 1 (lanes $1-6$ ) or at the end of the preincubation and just before the addition of NTPs in step 2 (lanes 7-12). The results of control reactions to which no Sarkosyl was added are shown in lanes 1 and 7 . The addition of Sarkosyl to a final concentration of $0.001 \%$ or $0.005 \%$ at either the beginning or the end of the preincubation had little effect on levels of transcription (cf. lanes 2 and 3 with lanes 8 and 9|. On the other hand, the presence of $0.015 \%$ Sarkosyl during the preincubation abolished transcription (lane 4), while its addition after the preincubation of the gene and the factors (lane 10) allowed transcription to occur at control levels. The addition of higher concentrations of Sarkosyl at either the beginning or the end of the preincubation abolished transcriptional activity. (A very small amount of transcription can be detected in lanes 11 and 12 on long exposures of the autoradiograph. Its significance is addressed below.) This experiment demonstrates that the pathway of preinitiation complex formation by RNA polymerase III includes

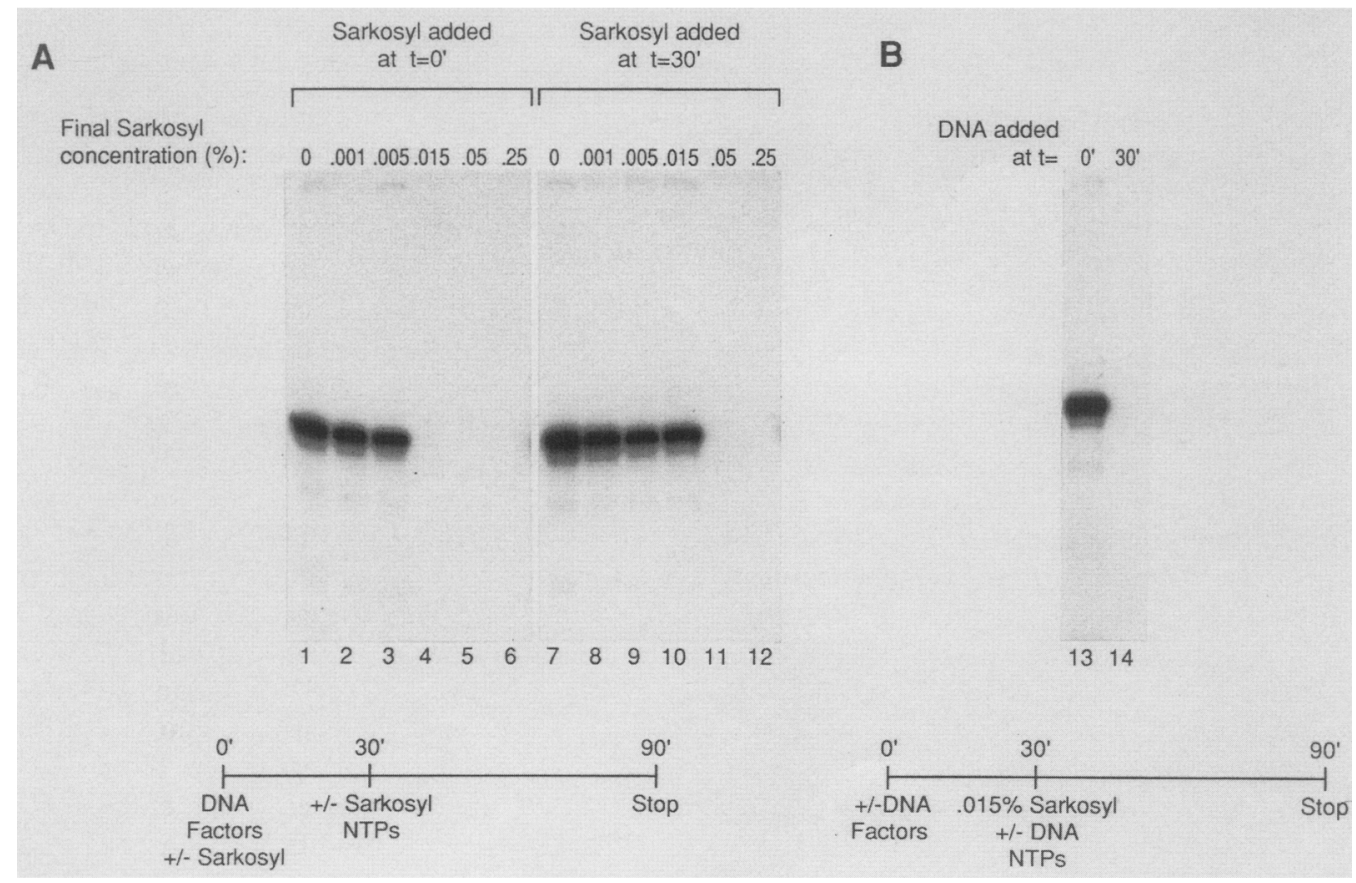

Figure 1. Formation of a preinitiation complex resistant to $0.015 \%$ Sarkosyl. $(A) \mathrm{pVA}_{\mathrm{I}}$ and fractions containing TFIIIB, TFIIIC, and RNA polymerase III, along with $\mathrm{MgCl}_{2}$, additional $\mathrm{KCl}$, and $\mathrm{H}_{2} \mathrm{O}$, were added at $t=0^{\prime}(0 \mathrm{~min})$. NTPs (including [ $\left.\alpha^{-{ }^{32}} \mathrm{P}\right] \mathrm{GTP}$ in $2.8 \mu \mathrm{l}$ were added to start transcription at $t=30^{\prime}(30 \mathrm{~min})$, and a stop mix was added at $t=90^{\prime}(90 \mathrm{~min})$. Final reaction volumes during transcription were $25 \mu \mathrm{l}$ in all cases. Sarkosyl was added either before the mixing of template DNA and fractions (lanes 1-6) or just before the addition of NTPs (lanes 7-12). The concentrations of Sarkosyl shown above the lanes are the final concentrations during the transcription reactions. Reactions products were processed as described in Materials and methods. $(B)$ Preincubations and transcription reactions were as described for $A$, except that for both lanes, Sarkosyl was added to a final concentration of $0.015 \%$ just before the addition of NTPs, and, for lane 14, $\mathrm{pVA}_{\mathrm{I}}$ was added after Sarkosyl but before the NTPs. 
a step which is sensitive to disruption by $0.015 \%$ Sarkosyl.

It has been reported that complexes of TFIIIC, TFIIIB, and RNA polymerase III can form in the absence of template DNA (Wingender et al. 1986). To determine whether the $\mathrm{VA}_{\mathrm{I}}$ gene is required to confer resistance to $0.015 \%$ Sarkosyl, we performed the experiment diagrammed at the bottom of Figure 1B. Preincubations and transcription reactions were performed as described in Figure 1A, except that for lane 14 the template was not added until the end of the preincubation. The complete absence of transcription in lane 14 demonstrates that the template is required to confer resistance to $0.015 \%$ Sarkosyl, and that the Sarkosyl-sensitive step is presumably along the normal pathway of preinitiation complex formation on the $\mathrm{VA}_{\mathrm{I}}$ gene.

The results of additional Sarkosyl titrations (performed as in Fig. 1) are shown in Figure 2. All results are expressed as a percent of control reactions to which no Sarkosyl was added. The solid lines represent the results of reactions to which Sarkosyl was added at the beginning of the preincubation (as for the left-hand panel of Fig. 1A), whereas the dashed lines represent those to which Sarkosyl was added at the end of the preincubation (as for the right-hand panel of Fig. 1A). The data are from two sets of experiments, circles being from one series and squares from another. Although there is minor $(<20 \%)$ variability from experiment to experiment, it is clear that a preincubation of template and factors in the absence of NTPs led to the formation of a preinitiation complex which was resistant to disruption by $0.015 \%$ Sarkosyl.

Time course of formation of the complex resistant to $0.015 \%$ Sarkosyl

We measured the amount of time required for formation of the $0.015 \%$ Sarkosyl-resistant complex by adding Sar-
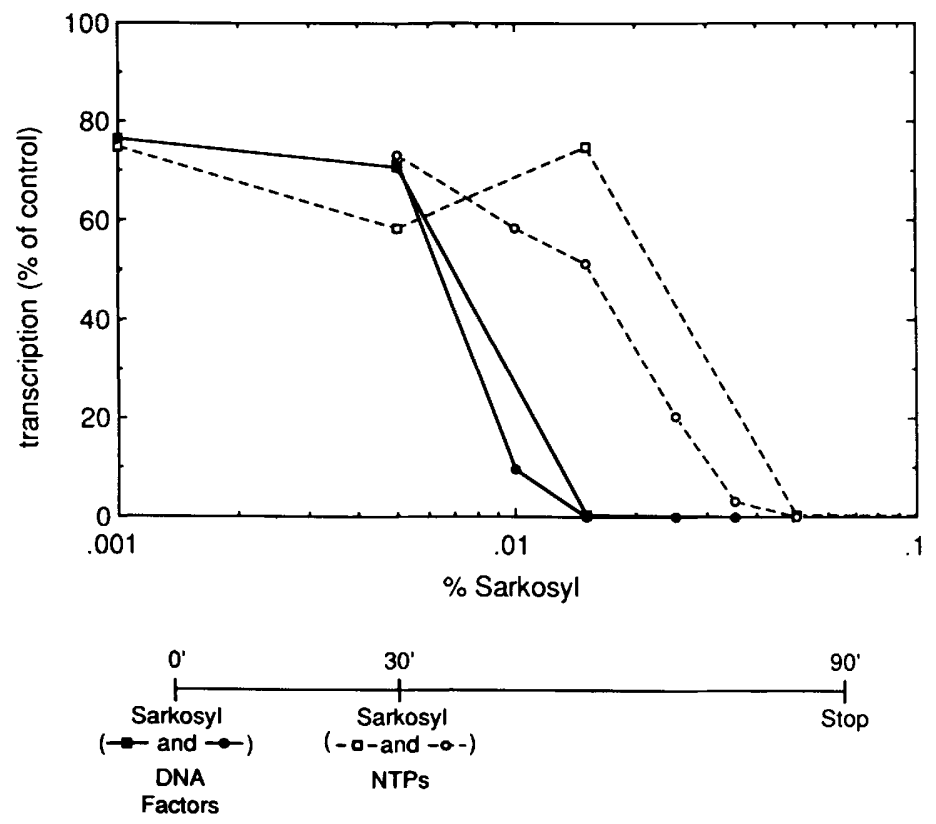

kosyl to a final concentration of $0.015 \%$ at variable times between 0 and $60 \mathrm{~min}$ after the beginning of a 60min preincubation. (See the diagram at the bottom of Fig. 3.) Figure 3 shows the results of these transcription reactions expressed as a percent of the radioactivity incorporated in the reaction to which Sarkosyl was added at the end of the preincubation. The formation of this complex was a relatively slow process with a $t_{1 / 2}$ of $\sim 14$ min. This suggests that the step sensitive to $0.015 \%$ Sarkosyl is not the first step in the formation of a transcription complex on the $\mathrm{VA}_{\mathrm{I}}$ gene, because this first step, the binding of TFIIIC to the promoter, is known from both template commitment (Lassar et al. 1983; Fuhrman et al. 1984; Bieker et al. 1985) and gel retardation (Hoeffler et al. 1988) assays to be a much faster process. Moreover, the kinetics observed here are very similar to the kinetics of formation of a rate-limiting complex on a 5S RNA gene (Bieker et al. 1985). Thus, the step blocked by $0.015 \%$ Sarkosyl may also be the ratelimiting step for the initiation of in vitro transcription on the $\mathrm{VA}_{1}$ gene.

\section{Factors required for the formation of the $0.015 \%$} Sarkosyl-resistant complex

To determine which factors are required to form a complex resistant to inhibition by $0.015 \%$ Sarkosyl, phosphocellulose fractions containing TFIIIB or TFIIIC and Sarkosyl were added sequentially as diagrammed in Figure 4. In each case, a 60-min preincubation was followed by a 60 -min transcription reaction. As in the experiment described above, the template was added at the beginning of the preincubation $(0 \mathrm{~min})$, and NTPs were added to start the transcription reaction $(60 \mathrm{~min})$. A fraction containing either TFIIIB or TFIIIC was added at the beginning of the preincubation $(0 \mathrm{~min})$, while the other fraction was added $30 \mathrm{~min}$ later. Sarkosyl was added to a final concentration of $0.015 \%$ either just before addition
Figure 2. Effect of Sarkosyl added before or after complex formation. Transcription reactions were performed as described in the legend to Fig. 1 and quantitated as described in Materials and methods. Levels of transcription were normalized to control reactions to which no Sarkosyl had been added. ( $\square$ and $\square$ ) The results of one experiment: 10 and the results of another. (The maximal level of transcription on this graph is $\sim 80 \%$ of control reactions because $60 \mathrm{~min}$ were required to form the maximum number of preinitiation complexes under the conditions employed.) (See Fig. 3.) 
Figure 3. Time course of formation of the preinitiation complex resistant to $0.015 \%$ Sarkosyl. The addition of $\mathrm{pVA}_{\mathrm{I}}$, fractions, $\mathrm{KCl}, \mathrm{MgCl}_{2}, \mathrm{H}_{2} \mathrm{O}$, NTPs, and stop mix was as described in the legend to Fig. 1, except that the total preincubation time was $60 \mathrm{~min}$. Sarkosyl was added at various times during the preincubation such that its final concentration during the transcription reaction would be $0.015 \%$. Quantitation was performed as described in Materials and methods; levels of transcription were normalized to the sample to which Sarkosyl was added at the end of the preincubation.
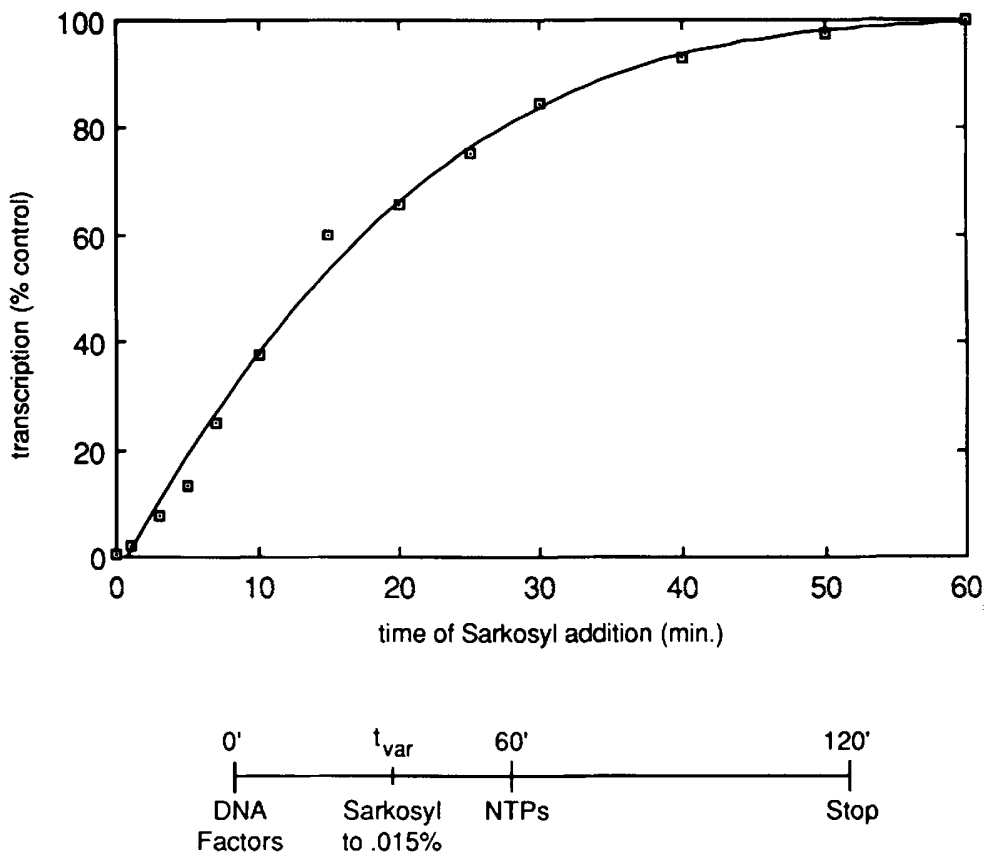

We were interested in determining whether RNA polymerase III was also required to confer resistance to $0.015 \%$ Sarkosyl. Because both of the phosphocellulose fractions (0.35 $\mathrm{M}$ and $0.6 \mathrm{M}$ steps) used in the experiment shown in Figure 4 contain RNA polymerase III in addition to TFIIIB and TFIIIC, we performed further purification of each of the components. RNA polymerase III derived from HeLa cell S100 extracts was purified over three columns, while TFIIIB and TFIIIC were separated from the RNA polymerase on DEAE-Sephadex A-25. (See Materials and methods for details.) Sarkosyl titrations performed as in Figure 2 with these more purified fractions were essentially identical to those with phosphocellulose fractions (data not shown). We employed these fractions in sequential preincubations as diagrammed at the bottom of Figure 5 . The addition of Sarkosyl after a preincubation of all components (lane 2) led to a small reduction in transcription compared to a control reaction to which no Sarkosyl had been added (lane complex of TFIIIC and the VA I gene (Lassar et al. 1983).

Figure 4. Formation of a complex resistant to $0.015 \%$ Sarkosyl requires TFIIIB and TFIIIC. $\mathrm{pVA}_{\mathrm{I} /}$ $\mathrm{KCl}, \mathrm{MgCl}_{2}, \mathrm{H}_{2} \mathrm{O}$, NTPs, and stop mix were added as described in the legend to Fig. 1, except that total preincubation time was $60 \mathrm{~min}$. For lanes $1-3$ a phosphocellulose fraction containing TFIIIC was added at $t=0^{\prime}(0 \mathrm{~min})$, and a phosphocellulose fraction containing TFIIIB was added at $t=30^{\prime}(30 \mathrm{~min})$. (Both fractions contain RNA polymerase III.) For lanes 4-6 the fraction containing TFIIIB was added at $t=0^{\prime}$, and the fraction containing TFIIIC was added at $\mathbf{t}=30^{\prime}$. No Sarkosyl was added to samples 1 and 4 , whereas Sarkosyl to a final concentration of $0.015 \%$ in the transcription reaction was added either just before the addition of NTPs to start transcription at $t=60^{\prime}(60 \mathrm{~min}$ ) (lanes 2 and 5$)$ or just before the addition of the second fraction at $t=30^{\prime}$ (lanes 3 and 6$)$. Incorporation of $\left[\alpha^{-32} \mathrm{P}\right] \mathrm{GTP}$ in lanes 2 and 5 were $55 \%$ and $51 \%$ of the respective controls (lanes 1 and 4$)$.

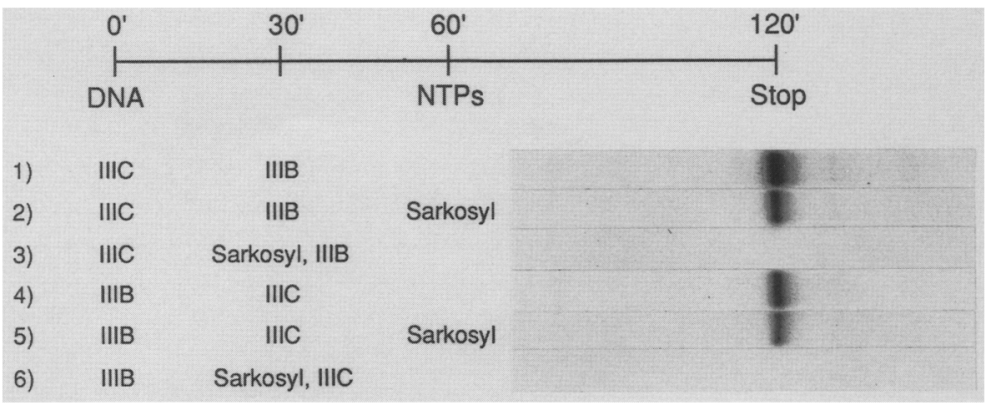




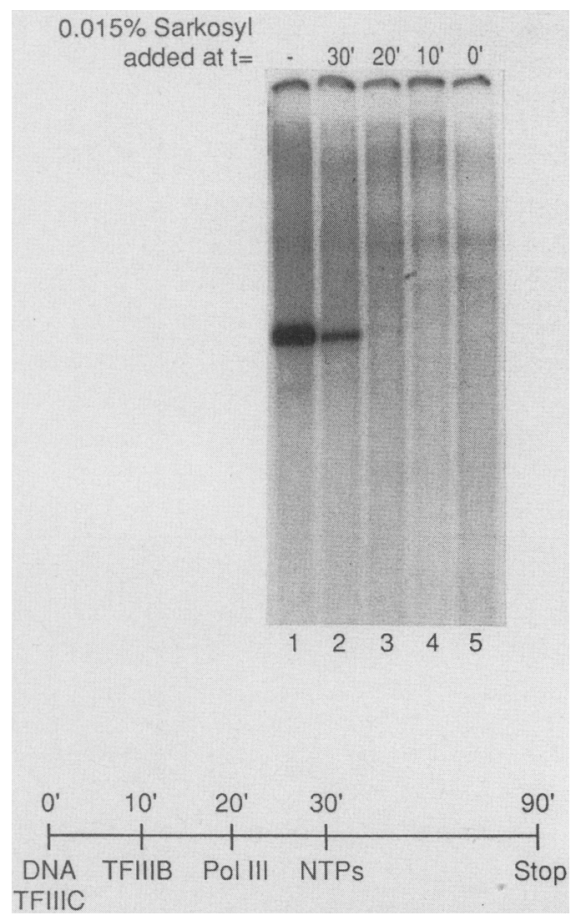

Figure 5. Formation of the $0.015 \%$ Sarkosyl-resistant complex also requires RNA polymerase III. The experimental procedure was similar to that employed for Fig. 4, except that the total preincubation time was $30 \mathrm{~min}$, and the fractions (DEAE-Sephadex fractions containing TFIIIB or TFIIIC and RNA polymerase III prepared as described in Materials and methods/ were in all cases added in the order TFIIIC, TFIIIB, and RNA polymerase III. Sarkosyl was always added immediately prior to the addition of the NTPs or protein fraction. Incorporation of $\left[\alpha^{-32} \mathrm{P}\right]$ GTP in lane 2 was $38 \%$ of control (lane 1$)$.

1); this correlates well with what was observed with phosphocellulose fractions (cf. lanes 1 and 2 of Fig. 4; see figure legends for quantitation). On the other hand, the addition of Sarkosyl to $0.015 \%$ at any earlier stage of complex formation completely inhibited transcription (lanes 3-5). Thus, the formation of a $0.015 \%$ Sarkosylresistant complex required the presence of all three components known to be involved in the transcription of class III genes.

\section{Reinitiation is limited by $0.05 \%$ Sarkosyl}

Close inspection of very long exposures of the autoradiograph shown in Figure 1 revealed that low levels of transcriptional activity persisted when Sarkosyl was added to $0.05 \%$ or $0.25 \%$ at the end of the preincubation (data not shown). To investigate whether these low levels of transcription resulted from single rounds of transcription, we performed time courses of transcription as diagrammed at the bottom of Figure 6. The template and factors were preincubated as described for the previous experiments, and Sarkosyl was added to a final concentration of either $0.015 \%$ (Fig. 6A) or $0.05 \%$ (Fig. $6 \mathrm{~B}, \mathrm{C}$ ) just prior to the addition of NTPs. Transcription reactions were stopped after the time shown above each lane.

The data shown in Figures $1-5$ imply that if reinitiation (defined as the production of more than one transcript from a particular complex) were occurring in this system, then the addition of $0.015 \%$ Sarkosyl after a preincubation did not preclude multiple rounds of transcription from active complexes, as overall transcriptional levels were not significantly changed from levels seen in the absence of Sarkosyl. The time course of transcription in the presence of $0.015 \%$ Sarkosyl (Fig. 6A and data not shown) is consistent with this assumption, as the rate of $\mathrm{VA}_{\mathrm{I}}$ transcript production was constant for over $1 \mathrm{hr}$. On the other hand, when Sarkosyl was added to $0.05 \% 30 \mathrm{sec}$ before the addition of NTPs, transcript production was already maximal by 2 min after the start of transcription. This is evident from the constant signal in all lanes of Figure 6B. (Fig. 6A and B of this figure are from the same autoradiograph, thus allowing a direct visual comparison of the results of multiple- and singleround transcription. Later time points are not presented for the multiple-round transcription (Fig. 6A) because the autoradiograph is greatly overexposed.

We performed another experiment to determine how rapidly maximal transcript production was attained in the presence of $0.05 \%$ Sarkosyl, and the results are shown in Figure 6C. Full-length $\mathrm{VA}_{\mathrm{I}}$ RNA first appeared by $30 \mathrm{sec}$ after the addition of NTPs, and its level was maximal by $60-75 \mathrm{sec}$. This time course clearly suggests that $0.05 \%$ Sarkosyl blocked reinitiation.

The presence of $V A_{I}$ transcripts shorter than the fulllength product is also suggestive of limited reinitiation. These transcripts, which are clearly visible in the slightly overexposed autoradiograph shown in Figure 6C, most likely resulted from the release of RNA from ternary complexes containing polymerases paused at specific sites. Note that the amount of the longest putative pausing product is maximal at $45 \mathrm{sec}$ of transcription, while a shorter one is maximal at $30 \mathrm{sec}$, suggesting that the shorter products are being chased into full-length transcripts. Sarkosyl has been shown to affect elongation by RNA polymerase II by inducing pausing downstream of the start site of a number of promoters, including adenovirus major late (Hawley and Roeder 1985) and HIV-1 and HIV-2 (Toohey and Jones 1989). Its effect on transcription elongation by RNA polymerase II appears to be much more stringent than its effect on RNA polymerase III, as the block to elongation on at least some fraction of the templates transcribed by RNA polymerase II could not be overcome by longer incubations (Hawley and Roeder 1985).

Sarkosyl at this higher concentration $\{0.05 \%)$ clearly limits reinitiation, and the most likely interpretation of these results is that it strictly blocks reinitiation by RNA polymerase III. To confirm this hypothesis, we performed the experiment diagrammed at the bottom of Figure 7 . The template and factors were preincubated as in the experiments described above; however, in contrast to those experiments, transcription was initiated by the addition of NTPs in the absence of Sarkosyl. For 


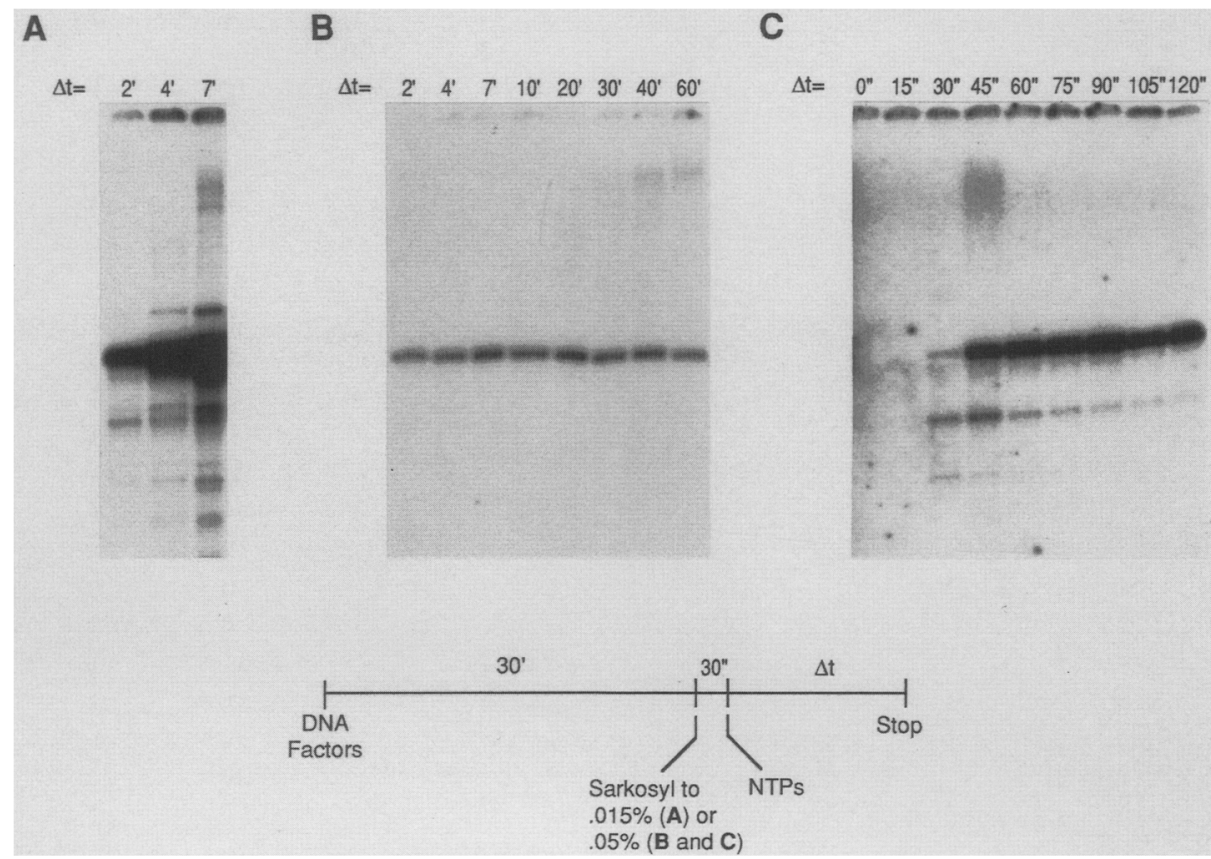

Figure 6. Addition of Sarkosyl to $0.05 \%$ after complex formation appears to allow only a single round of transcription. $\mathrm{pVA}_{\mathrm{I}}$ and factors were preincubated for $30 \mathrm{~min}$ as described in the legend to Fig. 1 . Sarkosyl was added to a final concentration of $0.015 \%(A)$ or $0.05 \%(B$ and $C)$ just before the addition of NTPs. Transcription reactions were terminated by the addition of stop mix after the number of minutes $\{A$ and $B \mid$ or seconds $|C|$ shown above the lanes and were processed as described in Materials and methods. $A$ and $B$ are from the same autoradiograph, while $C$ is the result of a separate experiment.

Figure 7A, transcription was allowed to proceed for the amount of time shown above the lanes, at which point the stop mix was added. This shows the linear rate of $\mathrm{VA}_{\mathrm{I}}$ transcript production for $1 \mathrm{hr}$ under these conditions. For Figure $7 \mathrm{~B}$, the times shown above the lanes represent the number of minutes between the addition of NTPs and the addition of Sarkosyl to a final concentration of $0.015 \%$; transcription reactions were stopped 60 min after the addition of NTPs. Note that each of the signals in Figure $7 \mathrm{~B}$ is equal in intensity to the signal resulting from $60 \mathrm{~min}$ of transcription in Figure $7 \mathrm{~A}$, directly supporting the claim made above that $0.015 \%$ Sarkosyl has no effect on reinitiation.

For Figure 7C, Sarkosyl was added instead to $0.05 \%$ at the same time points as for the addition to $0.015 \%$ in Figure $7 \mathrm{~B}$, again with $60 \mathrm{~min}$ between the addition of NTPs and the end of the transcription reaction with the addition of stop mix. The close correspondence between the signals in the corresponding lanes of Figure 7A and C indicates that even after transcription initiation and reinitiation, $0.05 \%$ Sarkosyl essentially acted as a stop mix by allowing elongation to proceed while strictly inhibiting reinitiation. The data in Figures 6 and 7 thus indicate that $0.05 \%$ Sarkosyl can be used to assay single rounds of transcription.

If $0.05 \%$ Sarkosyl indeed allows only single rounds of transcription from all complexes, as opposed to multiple rounds from a Sarkosyl-resistant fraction of the total, then the initiation of transcription with a subset of the NTPs prior to Sarkosyl addition should result in a level of transcription comparable to that observed when Sarkosyl is added first. We performed such experiments in which an NTP mixture lacking ATP, CTP, or UTP was added to start production of a short transcript prior to the addition of Sarkosyl and, subsequently, the missing NTP. Levels of transcription were indeed approximately equivalent to those in which Sarkosyl was added before the NTPS (data not shown), strongly suggesting that single rounds of transcription are being assayed. We also performed experiments using heparin under conditions recently reported to limit yeast RNA polymerase III to single rounds of transcription (Kassavetis et al. 1989). The levels of transcription observed under these conditions were very similar to those seen with $0.05 \%$ Sarkosyl (data not shown). This provides even stronger evidence that our conditions allow only single rounds of transcription.

We have made an estimate of the number of active complexes in these assays. We determined that for the assays presented in Figure 6B, approximately 1 in 2000 of the $\mathrm{VA}_{\mathrm{I}}$ templates present was transcribed. For the separate experiment presented in Figure 6C, roughly 1 in 5700 templates formed active complexes. Stated another way, in Figure $6 \mathrm{~B}, 550 \mathrm{fmoles}$ of $\mathrm{pVA}_{\mathrm{I}}$ produced 0.27 fmoles of $V A_{I}$ RNA, and in Figure 6C, 550 fmoles of $\mathrm{pVA}_{\mathrm{I}}$ produced 0.097 fmole of $\mathrm{VA}_{\mathrm{I}}$ RNA. We do not know the source of this variation, but we have noticed large variations in the levels of incorporation with the age of the $\left[\alpha^{-32}\right.$ P]GTP and the batch of NTPs used. We also estimate that under multiple-round transcription 


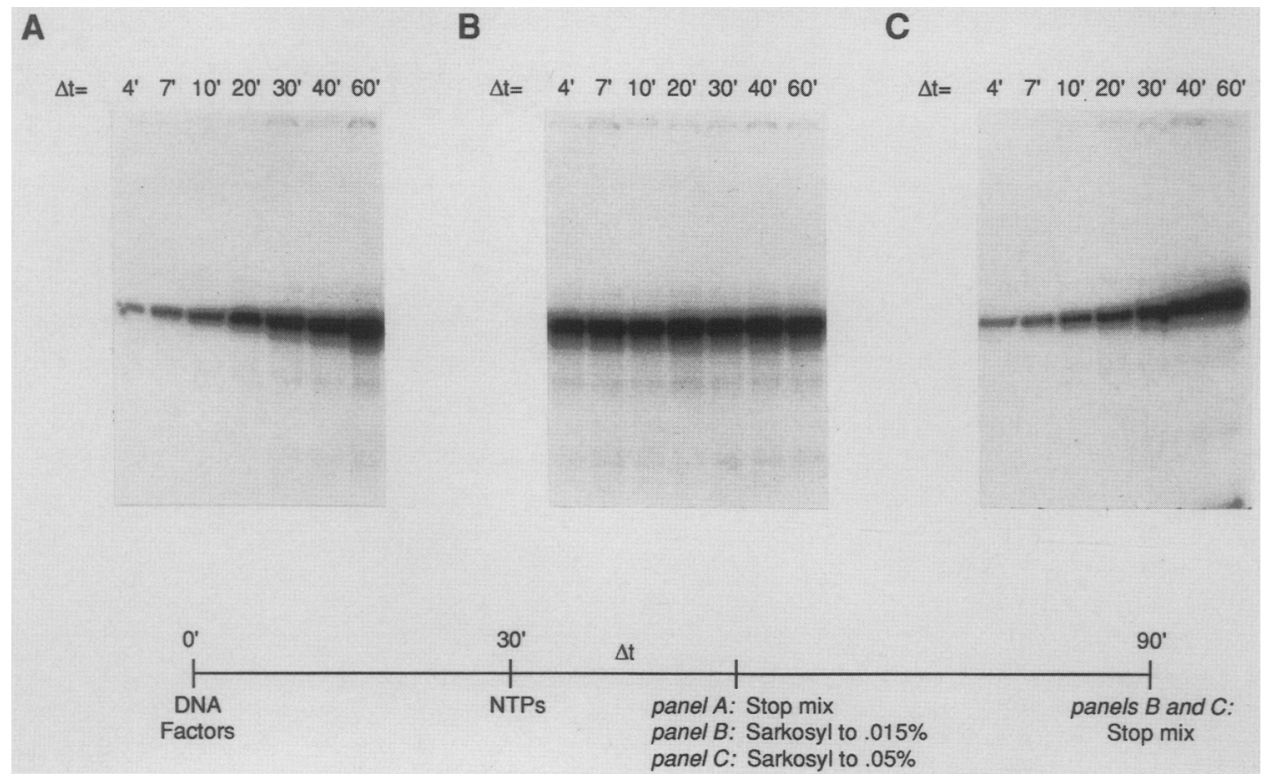

Figure 7. Sarkosyl at $0.015 \%$ does not affect transcription from complexes which have begun initiation, whereas $0.05 \%$ Sarkosyl inhibits reinitiation. Preincubations were as described in the legend to Fig. 1. NTPs were added to start transcription at $t=30^{\prime}(30$ $\mathrm{min}$ ) in the absence of Sarkosyl. (A) Transcription reactions were terminated after the number of minutes shown by the addition of stop mix. $(B$ and $C$ ) Sarkosyl was added to a final concentration of $0.015 \%(B)$ or $0.05 \%(C)$ after the number of minutes shown. Transcription reactions were terminated at $\mathrm{t}=90^{\prime}(90 \mathrm{~min})$ (i.e., $60 \mathrm{~min}$ after the addition of NTPs).

conditions, active complexes support several hundred rounds of reinitiation per hour.

\section{E1A expression results in an increased number of functional complexes}

Our previous results (Hoeffler and Roeder 1985; Hoeffler et al. 1988) indicated that the stimulation of transcription by RNA polymerase III in extracts made from cells infected by adenovirus (and expressing ElA) was mediated by an increase in the level of a more active form of TFIIIC, while overall levels of TFIIIC, as measured by template commitment assays, were unchanged. Template commitment assays do not indicate, however, whether a stimulation of transcription results from an increase in the number of active transcription complexes or from an increase in the specific activity of a constant number of functional complexes (resulting, for example, from an increased frequency of polymerase reinitiation). To determine which of these possible mechanisms was responsible for the ElA-mediated increase in class III transcriptional activity, we used the ability of $0.05 \%$ Sarkosyl to block the reinitiation of transcription to assay single rounds of transcription in fractions derived from stimulated and unstimulated extracts. The experimental protocol is diagrammed in Figure 8.

For this analysis, HeLa cells were first slowed in their growth by reducing the concentration of serum present in the medium (as detailed in Materials and methods). Then they were infected either with dl312, the adenovirus mutant lacking a functional E1A gene, or with dl309, the parent virus of $\mathrm{dl} 312$ having a wild-type E1A gene. Nuclear extracts were made at $6 \mathrm{hr}$ postinfection and assayed for transcriptional activity. The dl309-infected cell extract had 7- to 10-fold higher activity than the control dl312-infected cell extract (data not shown). To deplete the extracts of contaminating nucleotides, which could complicate the analysis of single rounds of transcription, they were subjected to chromatography on parallel phosphocellulose columns. After washing to remove unbound nucleotides, TFIIB, TFIIIC, and RNA polymerase III were eluted with a single step at $0.6 \mathrm{M}$ $\mathrm{KCl}$. As indicated in Figure 8, activity was assayed either by preincubation of the $\mathrm{VA}_{\mathrm{I}}$ template with dl309- or dl312-derived fractions prior to the addition of NTPs and a 1-hr transcription reaction $(\mathrm{A})$ or by the addition of Sarkosyl to $0.05 \%$ just before the initiation of transcription in these fractions (B); as shown above, the latter conditions should limit transcription to a single round. The autoradiograph of the resultant $V_{A_{I}}$ transcripts are shown at the bottom of the figure.

Figure 8A shows the level of stimulation of transcription after fractionation of the extracts. Equivalent volumes of fractions, which in this case correspond to cell equivalents, were assayed under conditions permitting multiple rounds of transcription. Essentially the same level of stimulation of transcription was also observed under single-round transcription conditions (Figure 8B). The autoradiograph shown in Figure 8B was exposed much longer than the corresponding autoradiograph used for Figure 8A, to compensate for the greatly different intensities in signals /see figure legend for details); in any case, there was a clear difference between 
Figure 8. Enhanced $\mathrm{VA}_{\mathrm{I}}$ transcription in fractions derived from cells infected with adenovirus expressing E1A results from an increased number of functional preinitiation complexes. Cells were slowed in their growth and infected with dl309 or dl 312 adenoviruses, and nuclear extracts were prepared as described in Materials and methods. Extracts were fractionated over phosphocellulose as described in Materials and methods, and the $0.6 \mathrm{M}$ step fraction /containing TFIIIB, TFIIIC, and RNA polymerase III) was used in transcription assays as diagrammed. $(A) 1.5,2.5,3.5$, or 4.5 $\mu l$ of a fraction derived from dl309- or dl312-infected cell extracts was preincubated with $\mathrm{pVA}_{\mathrm{I}}, \mathrm{MgCl}_{2}$, additional $\mathrm{KCl}$, and $\mathrm{H}_{2} \mathrm{O}$ for 60 min prior to the addition of NTPs. Transcription reactions were terminated $60 \mathrm{~min}$ later, and samples were processed as described in Materials and methods. The autoradiograph shown was exposed for $2.5 \mathrm{hr}$ without an intensifying screen. $(B)$ Preincubations and transcription reactions were exactly as described for $A$, except that Sarkosyl was added to a final concentration of $0.05 \%$ just before the addition of NTPs. The autoradiograph shown was exposed for $36 \mathrm{hr}$ at $-70^{\circ} \mathrm{C}$ with an intensifying screen.
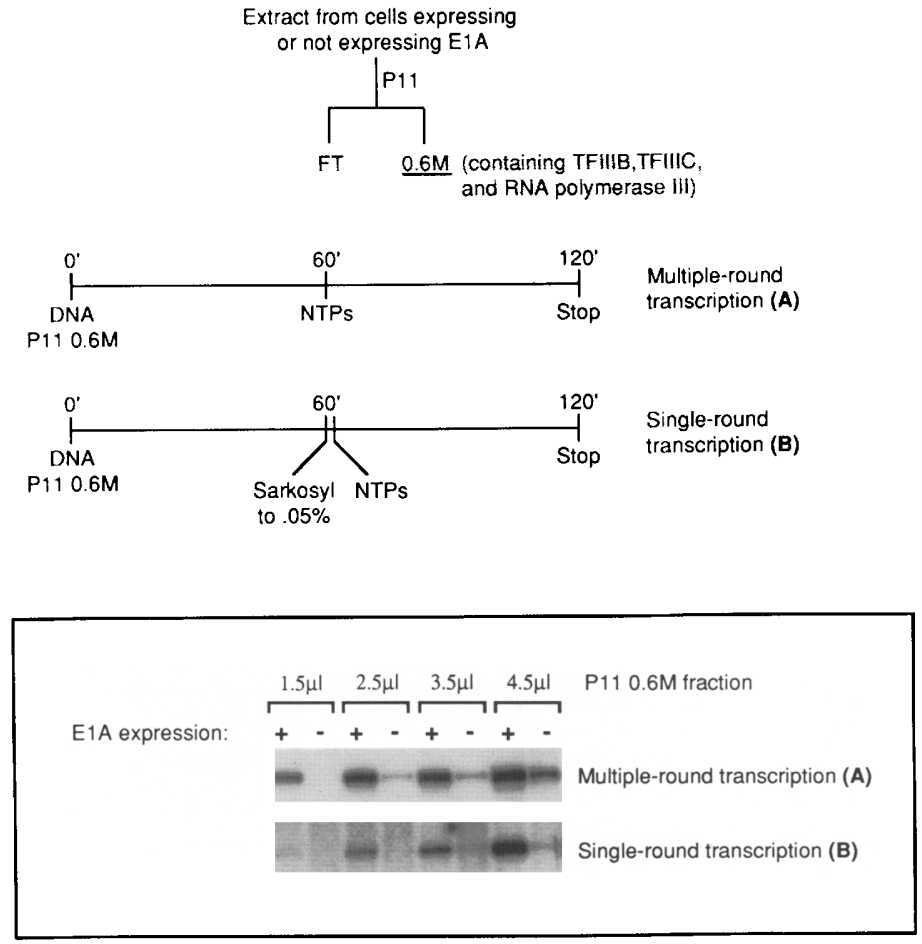

the levels of transcription in fractions derived from dl309- and dl312-infected cell extracts even when only a single round of transcription was permitted. This indicates that the stimulation of transcription resulted largely or entirely from an increase in the number of functional transcription complexes rather than from an increase in rates of reinitiation or elongation from an unchanged number of complexes.

\section{Discussion}

An understanding of the regulation of gene expression in eukaryotes requires detailed mechanistic information about the steps along the pathway of transcription complex formation and the initiation of transcription. The action of regulatory factors can be understood fully only by understanding which steps are rate limiting for transcription and how regulatory factors affect these steps. We used Sarkosyl to dissect functional steps in the assembly of a transcription complex on the $\mathrm{VA}_{\mathrm{I}}$ gene, and we demonstrated the utility of this approach in determining the mechanism of the ElA-mediated stimulation of transcription of the $\mathrm{VA}_{\mathrm{I}}$ gene.

\section{Complexes resistant to Sarkosyl}

Previous studies have indicated that the general order of association of proteins with the $\mathrm{VA}_{\mathrm{I}}$ promoter is TFIIIC, TFIIIB, RNA polymerase III, and that the resulting complexes are stable when challenged with competing templates (Lassar et al. 1983; Fuhrman et al. 1984; Bieker et al. 1985). The model shown in Figure 9 summarizes our present data about the effects of Sarkosyl on the func- tion of these complexes. As indicated, 0.015\% Sarkosyl blocks the formation of a complex (complex I) whose function, once formed, is otherwise unaffected by this concentration of Sarkosyl. The simplest interpretation of our results (Figs. 4 and 5), showing that resistance of transcription to $0.015 \%$ Sarkosyl requires preincubation of the VA $\mathrm{VA}_{\mathrm{I}}$ promoter with TFIIIC, TFIIIB, and RNA polymerase III, is that the resulting Sarkosyl-resistant complex involves stoichiometric interaction of all the factors. We have not excluded the possibility, however, that one of the components acts catalytically in forming a functional preinitiation complex that is resistant to Sarkosyl, nor do we know exactly which protein-DNA or protein-protein interaction is sensitive to Sarkosyl.

RNA polymerase III itself also appears to be required for the formation of complex I (see Fig. 5), but may not be required for its maintenance. The latter is indicated by the ability of RNA polymerase III to exhibit multiple rounds of initiation, elongation, and termination in the presence of $0.015 \%$ Sarkosyl (present data) and by the corresponding inability of the polymerase to remain stably bound to a promoter complex containing TFIIIC and TFIIIB when challenged by a second equivalent complex formed in the absence of any RNA polymerase (Bieker et al. 1985). These latter studies, however, employed the $5 \mathrm{~S}$ gene, as well as the regulatory factor TFIIIA, whereas gel filtration studies (Carey et al. 1986) have indicated that RNA polymerase III can be stably bound in a complex on the $\mathrm{VA}_{\mathrm{I}}$ gene under conditions where it dissociates from a complex on the $5 S$ gene. Thus, there are two likely explanations for the existence of multiple rounds of transcription on the $\mathrm{VA}_{\mathrm{I}}$ gene in the presence of $0.015 \%$ Sarkosyl: 1) the initial formation 


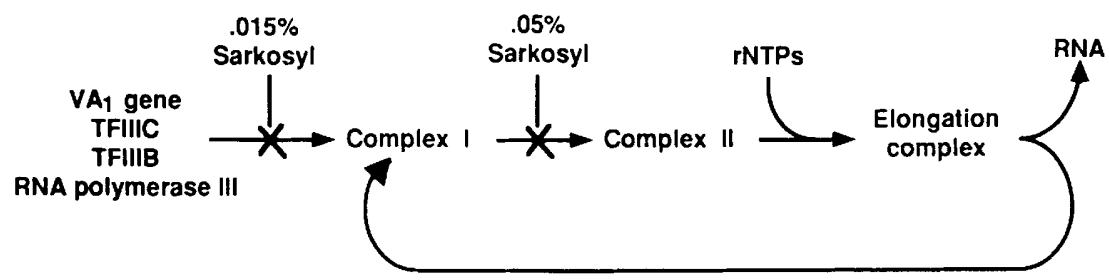

Figure 9. Model for the pathway of preinitiation complex assembly on the $\mathrm{VA}_{1}$ gene. This model summarizes our current data on the steps in transcriptional complex formation inhibited by Sarkosyl. A single arrow does not imply that there is only one biochemical step involved; indeed, it is likely that the step inhibited by $0.015 \%$ Sarkosyl is preceded by a number of other steps. (For details, see Discussion.)

of complex I, requiring RNA polymerase III, leads to a structural transformation in the $\mathrm{VA}_{\mathrm{I}}$-TFIIIC-TFIIIB complex such that the Sarkosyl-sensitive step is not encountered during subsequent rounds of initiation, or 21 RNA polymerase III is actually a stably-bound component of complex I and does not dissociate completely from the $\mathrm{VA}_{\mathrm{I}}$-TFIIIC-TFIIIB complex during transcription.

Complex I exhibits a number of similarities to the previously defined rate-limiting complex on the $5 \mathrm{~S}$ gene (Bieker et al. 1985). The kinetics of formation of these complexes are very similar, with a $t_{1 / 2}$ of about $14 \mathrm{~min}$, and all of the known protein components (TFIIIC, TFIIIB, RNA polymerase III, and, for the 5 S gene, TFIIIA) are required in each case. Formation of the rate-limiting complex, however, also required the presence of a nucleotide (Bieker et al. 1985; Bieker and Roeder 1986), whereas the $0.015 \%$ Sarkosyl-resistant complex was formed in the absence of nucleotides. This difference could reflect dissimilarities in the assembly of complexes on the $5 \mathrm{~S}$ and $\mathrm{VA}_{\mathrm{I}}$ genes, or it may indicate that these steps, although apparently related kinetically, are distinct from each other.

The present studies have also defined a second complex (complex II in Fig. 9) whose formation is blocked by $0.05 \%$ Sarkosyl but which, once formed, can still initiate a single round of transcription at this concentration of detergent. This defines a step that, in contrast to the one inhibited by $0.015 \%$ Sarkosyl, is encountered during each round of initiation and permits the assay of single rounds of transcription by RNA polymerase III. Nucleoside triphosphates are also not required for the formation of complex II; this property distinguishes complex II from the elongation complex containing template, elongating RNA polymerase, and nascent RNA. The relationship of complexes I and II is still unclear; they may differ as a result of a structural transition that is analogous, for instance, to the closed-to-open promoter conversion in prokaryotic systems (for review, see von Hippel et al. 1984), or they may differ by the presence of an additional cofactor. In this regard, it has been reported that TFIIIC can be split into two components, TFIIIC1 and TFIIIC2 (Dean and Berk 1987; Yoshinaga et al. 1987), the latter being involved in the formation of the initial stable complex. We have not been able to investigate the role of TFIIICl or possible alternative complex formation pathways at this time because we have been unable to detect separable activities (R. Kovelman and R.G. Roeder, unpubl.), even with extensive purification of TFIIIC (Cromlish and Roeder 1989).

\section{Comparisons between RNA polymerase III- and RNA polymerase II-dependent promoters}

There are both similarities and differences between the effects of Sarkosyl on the $\mathrm{VA}_{\mathrm{I}}$ gene (this report) and on the adenovirus major late (ML) gene (Hawley and Roeder 1985). Each transcription system shows two distinct steps sensitive to different concentrations of Sarkosyl, and in each case the data are consistent with transcription being limited to a single round under certain conditions. The specific effects of particular Sarkosyl concentrations, however, differed for the $\mathrm{VA}_{\mathrm{I}}$ and $\mathrm{ML}$ promoters. Thus, although the addition of $0.015 \%$ Sarkosyl at the beginning of the preincubation completely blocked transcription in each system, addition after the preincubation restricted transcription by RNA polymerase II to a single round but was without any detectable effect on reinitiation by RNA polymerase III. In other words, a step sensitive to disruption by $0.015 \%$ Sarkosyl is encountered during each round of transcription initiation by RNA polymerase II but is encountered only once [i.e., at the formation of complex I (Fig. 9)] during transcription by RNA polymerase III. This difference may reflect the distinct characteristics of stable complexes on class II versus class III genes; thus, all of the accessory factors required for initiation by RNA polymerase III can be sequestered into a stable promoter complex (Lassar et al. 1983; Bieker et al. 1985), whereas some of the accessory factors required by RNA polymerase II cannot be (Van Dyke et al. 1989). Another difference is that a higher concentration of Sarkosyl $(0.05 \%)$ was required to block the reinitiation of transcription by RNA polymerase III. Moreover, and significantly, nucleotides were not required to form Sarkosylresistant complexes capable of supporting single rounds of transcription by RNA polymerase III, whereas the apparently analogous conversion of the class II rapid start complex to a Sarkosyl-resistant complex required the presence of NTPs (Hawley and Roeder 1985). This difference in nucleotide requirements may correspond to the demonstrated need for a hydrolyzable $\beta-\gamma$ bond in ATP or an ATP analog for transcription in the class II system (Bunick et al. 1982; Sawadogo and Roeder 1984) but not 
in the class III system (Bunick et al. 1982; Carey et al. 1986).

\section{Mechanisms of stimulation of transcription}

The adenovirus ElA protein stimulates the transcription of a number of viral and cellular genes (for review, see Berk 1986), and these effects appear to be mediated via a number of different cellular transcription factors. For example, the cellular factors E2F and E4F have been implicated as targets for E1A activation of the adenovirus E2A and E4 genes, respectively (Kovesdi et al. 1986a,b; Lee and Green 1987; Raychaudhuri et al. 1987; Hardy et al. 1989|, whereas mutagenesis has demonstrated the importance of the TATA element, and thus a general transcription factor that interacts directly (TFIID) or indirectly (e.g., TFIIB, TFIIE, or RNA polymerase II) with this element, in E1A action on the adenovirus E1B (Wu et al. 1987) and human $h s p 70$ (Simon et al. 1988) genes. TFIIIC was shown to be another target for E1A activation by the apparent induction of a distinct form of the factor with higher transcriptional activity on adenovirus infection (Hoeffler et al. 1988). For a number of these cases, phosphorylation has been implicated in the modulation of transcriptional activity (Hoeffler et al. 1988; Bagchi et al. 1989; Raychaudhuri et al. 1989), while in other cases, transcriptional activation by E1A appears to require the activity of a viral early protein from the E4 coding region (Babiss 1989; Hardy et al. 1989; Huang and Hearing 1989; Reichel et al. 1989|. In spite of the increased understanding of some of the direct and indirect effects of E1A, the biochemical mechanisms by which levels of transcription are increased-in particular, the steps most closely associated with the initiation of transcription at the target gene-are still unknown. In fact, the stimulation of RNA polymerase II transcription by upstream promoter-binding factors, some of which have been extensively characterized with respect to activation domains (for review, see Maniatis et al. 1987; Ptashne 1988), is also not understood mechanistically. In at least some cases, quantitative and/or qualitative effects of the regulatory proteins on the basal transcription complex have been observed (Horikoshi et al. 1988a,b; Workman et al. 1988).

Previous results of in vitro transcription on fractionated extracts (Hoeffler and Roeder 1985; Yoshinaga et al. 1986) and of gel retardation assays (Hoeffler et al. 1988) have clearly implicated TFIIIC in ElA-mediated enhancement of $V_{I}$ transcription. It was reported on the basis of template commitment assays that adenovirus infection led to a quantitative increase in the total amount of TFIIIC that could bind to the $\mathrm{VA}_{1}$ gene (Yoshinaga et al. 1986), but our data indicated that there was no such change in total factor levels (Hoeffler et al. 1988). Taking advantage of our ability to measure single rounds of transcription, we demonstrate here (Fig. 8) that this stimulation of transcription results from an increased number of transcription complexes. It may appear that this result contradicts our previous finding, which was based on template commitment assays, that overall levels of TFIIIC did not change; however, the template commitment assay is a DNA binding assay and does not distinguish between active and inactive complexes. We also showed, by gel retardation assays, that ElA expression resulted in a marked increase in the proportion of TFIIIC that was transcriptionally active (Hoeffler et al. 1988; Kovelman et al. 1989; R. Kovelman and R.G. Roeder, unpubl.). Therefore, template commitment assays, gel retardation assays, and single-round transcription assays indicate, altogether, that the E1Amediated enhancement of $\mathrm{VA}_{\mathrm{I}}$ transcription results from an increased number of preinitiation complexes containing a transcriptionally active form of TFIIIC. Mechanistically, this is currently the best understood example of ElA action at the promoter level, whether this action is direct or indirect. Even if the stimulation of transcription by E1A operates via more than one pathway, this system is likely to provide information toward an understanding of other mechanisms.

Stimulation of $\mathrm{VA}_{\mathrm{I}}$ transcription in vitro that results from an increased number of active complexes could also be of direct relevance in vivo during the course of adenovirus infection. The levels of $V_{A_{I}}$ RNA increase dramatically only after viral replication (Söderlund et al. 1976); this may be caused not only by an increased number of templates, but also by a greater proportion of those templates being in an active state. Immediately after replication, $\mathrm{VA}_{\mathrm{I}}$ templates may form either active or inactive transcription complexes, and the relative proportions of the different forms of the key initiation factor TFIIIC may determine overall levels of $\mathrm{VA}_{\mathrm{I}}$ transcription. It has been demonstrated under various in vitro conditions that TFIIIA or TFIID can prevent the nucleosome-mediated repression of transcription (Bogenhagen et al. 1982; Gottesfeld and Bloomer 1982; Workman and Roeder 1987), and that the pseudorabies virus immediate early protein, which can stimulate the transcription of many of the same genes as the adenovirus E1A protein, further potentiates the formation of active transcription complexes on the adenovirus ML promoter under nucleosome assembly conditions (Workman et al. 1988). The regulation of transcriptional levels via competition between the formation of active and inactive complexes may be a significant mode of regulation of all multicopy genes and may also be relevant for the regulation of some single-copy genes. Sarkosyl and other inhibitors of particular steps of transcription will continue to be useful in helping to delineate the steps themselves as well as to determine how various regulatory proteins affect the key rate-limiting steps.

\section{Materials and methods}

\section{Cells and viruses}

Maintenance of HeLa cells (obtained from G. Attardi) in standard Joklik minimal essential medium (MEM) containing 5.0\% bovine calf serum or low-serum $(0.5 \% \mathrm{BCS})$ Joklik-MEM was as described previously (Hoeffler et al. 1988).

Adenovirus type 5 mutants dl309 (obtained from L. Babiss) and $\mathrm{dl} 312$ (obtained from $\mathrm{H}$. Ginsberg) were titrated on HeLa or 293 cell monolayers, respectively, by plaque assay (Williams 
1970|. Except for the use of Ad5 d1309 instead of wild-type Ad2, infections of HeLa cells grown in $0.5 \%$ serum-containing medium were as described previously (Hoeffler et al. 1988).

\section{Extracts and fractionation}

Nuclear extracts were prepared from uninfected HeLa cells essentially as described elsewhere (Dignam et al. 1983), whereas nuclear extracts from virus infected cells were prepared according to the slightly modified method of Hoeffler et al. (1988).

Phosphocellulose fractionation of uninfected cell nuclear extracts on phosphocellulose (Whatman P11) was performed essentially as described previously for $\$ 100$ extracts (Segall et al. 1980). Extracts were loaded onto columns equilibrated in buffer A [20 mM HEPES- $\mathrm{NaOH}$ (pH 7.9) or $20 \mathrm{~mm}$ Tris- $\mathrm{HCl}(\mathrm{pH} 7.9)$, $20 \%$ (vol/vol) glycerol, $0.2 \mathrm{mM} \mathrm{Na} 2$ EDTA, and $1 \mathrm{~mm}$ dithiothreitol] containing $0.1 \mathrm{M} \mathrm{KCl}$. The column was washed with this buffer, and proteins were sequentially step-eluted with buffer A containing $0.35 \mathrm{M} \mathrm{KCl}$ and $0.6 \mathrm{M} \mathrm{KCl}$. Protein concentrations were determined according to the method of Bradford (1976). Fractions containing peak concentrations of protein were pooled, dialyzed against buffer A plus $0.1 \mathrm{M} \mathrm{KCl}$ for 2-3 hours, and stored at $-70^{\circ} \mathrm{C}$. Most of the RNA polymerase III activity was in the $0.35 \mathrm{M} \mathrm{KCl}$ step, but approximately $10 \%$ was in the $0.6 \mathrm{M} \mathrm{KCl} \mathrm{step.} \mathrm{These} \mathrm{fractions} \mathrm{were} \mathrm{used} \mathrm{for} \mathrm{all}$ experiments except those for Figures 5 and 8.

Fractionation of infected-cell nuclear extracts (analyzed in Fig. 8) was performed essentially as described in the preceding paragraph, except that the $0.35 \mathrm{M} \mathrm{KCl}$ step was omitted. The single step at $0.6 \mathrm{M} \mathrm{KCl}$ therefore contained all of the proteins required for $\mathrm{VA}_{\mathrm{I}}$ transcription.

For further purification of TFIIIB and TFIIIC, phosphocellulose $0.35 \mathrm{M}$ and $0.6 \mathrm{M} \mathrm{KCl}$ steps prepared as described above were dialyzed against buffer B $[50 \mathrm{mM}$ Tris- $\mathrm{HCl}\langle\mathrm{pH} 7.9\}, 25 \%$ (vol/vol) glycerol, $0.1 \mathrm{mM} \mathrm{Na} 2$ EDTA, $1 \mathrm{mM}$ DTT, $0.5 \mathrm{~mm}$ phenylmethylsulfonyl fluoride] also containing $50 \mathrm{~mm}$ $\left(\mathrm{NH}_{4}\right)_{2} \mathrm{SO}_{4}$ for $3 \mathrm{hr}$. The dialyzed samples were loaded separately at $2 \mathrm{mg}$ of protein per milliliter of resin onto DEAE-Sephadex A-25 (Pharmacia) columns prepared according to Bitter $(1983)$ and equilibrated in buffer $\mathrm{B}$ plus $50 \mathrm{mM}\left(\mathrm{NH}_{4}\right)_{2} \mathrm{SO}_{4}$. Proteins were eluted from the columns with 6 column-volume gradients from $50 \mathrm{~mm}\left(\mathrm{NH}_{4}\right)_{2} \mathrm{SO}_{4}$ to $500 \mathrm{~mm}\left(\mathrm{NH}_{4}\right)_{2} \mathrm{SO}_{4}$ in buffer B. TFIIIB and TFIIIC eluted at low salt [100-130 mM $\left.\left(\mathrm{NH}_{4}\right)_{2} \mathrm{SO}_{4}\right]$, whereas the bulk of the RNA polymerase III eluted at high salt $\left[300-350 \mathrm{~mm}\left(\mathrm{NH}_{4}\right)_{2} \mathrm{SO}_{4}\right]$. These low salt fractions were used directly for the assays shown in Figure 5.

For the RNA polymerase III used in the experiment of Figure 5, 1 liter of HeLa cell S100 extract (prepared as described in Weil et al. 1979) was loaded onto a 300-ml phosphocellulose column equilibrated in buffer A plus $0.1 \mathrm{M} \mathrm{KCl}$. Proteins were eluted with a 4 column-volume gradient from $0.1 \mathrm{M} \mathrm{KCl}$ to 1.0 $\mathrm{M} \mathrm{KCl}$ in buffer A. Fractions containing the peak of polymerase activity were pooled and dialyzed against buffer $\mathrm{B}$ containing 50 $\mathrm{mM}\left(\mathrm{NH}_{4}\right)_{2} \mathrm{SO}_{4}$. Successive chromatography on DEAE-cellulose (Whatman DE52) and DEAE-Sephadex A-25 (Pharmacia), followed by step-elution from phosphocellulose to concentrate the sample eluted from Sephadex A-25, was performed essentially as described in Sklar and Roeder (1976), except that the final phosphocellulose column was run in $\mathrm{KCl}$ instead of $\left(\mathrm{NH}_{4}\right)_{2} \mathrm{SO}_{4}$. The fractions assayed in the experiment shown in Figure 5 were $>95 \%$ free of cross-contamination.

\section{Transcription assays}

Standard 25- $\mu$ l transcription reactions contained $70 \mathrm{mM} \mathrm{KCl}, 7$ $\mathrm{mM} \mathrm{MgCl}_{2}, 8 \%$ (vol/vol) glycerol, $8 \mathrm{~mm}$ HEPES-NaOH $\{\mathrm{pH} 7.9$ ), $0.4 \mathrm{mM}$ DTT, $5 \mathrm{~mm}$ creatine phosphate, $40 \mu \mathrm{g} / \mathrm{ml} \mathrm{pVA}_{\mathrm{y}}, 600 \mu \mathrm{M}$ each ATP, CTP, and UTP, and $12.5 \mu \mathrm{M}\left[\alpha^{-32} \mathrm{P}\right] \mathrm{GTP}(8.0 \mathrm{Ci} /$ mmole). Unlabeled nucleoside triphosphates were obtained from Pharmacia; $\left[\alpha^{-32}\right.$ P]GTP $[3000 \mathrm{Ci} / \mathrm{mmole})$ was obtained from Amersham. Sarkosyl ( $N$-lauroylsarcosine, sodium salt) was obtained from Sigma. Sarkosyl solutions were made up as a $20 \%$ (wt/vol) stock. [We noticed some variation in the concentration dependence of the Sarkosyl effects reported with the batch of Sarkosyl. A new solution must be titrated to determine the optimal concentrations for assaying complexes I or II (see Fig. 9l]. All concentrations of standard transcription reaction components as well as of Sarkosyl are expressed as final concentrations during the transcription reaction itself. Because all components except for the NTPs, Sarkosyl /when added after the preincubation), and some protein fractions (Fig. 4) were incubated from the beginning of the preincubation, the actual concentrations of $\mathrm{KCl}, \mathrm{MgCl}_{2}$, etc., were somewhat higher during the preincubation than stated above and in the figure legends.

Transcription reactions were stopped by the addition of $25 \mu \mathrm{l}$ of a mixture containing $100 \mathrm{mM}$ sodium acetate $(\mathrm{pH} 5.5), 0.4 \%$ SDS, $2 \mathrm{mg} / \mathrm{ml}$ yeast RNA, and $30 \mathrm{mM} \mathrm{Na}_{2}$ EDTA, followed by sequential extractions with 2.5 volumes of phenol and chloroform. RNA was precipitated by the addition of 2.5 volumes of a $90 \%$ ethanol/100 mM sodium acetate $(\mathrm{pH} 5.5)$ mixture. Pellets were dried and resuspended in $5 \mu \mathrm{H}_{2} \mathrm{O}$. Formamide $(10 \mu \mathrm{l})$, containing $0.1 \%$ bromophenol blue and $0.1 \%$ xylene cyanole, was added, and the samples were incubated for $5 \mathrm{~min}$ at $95^{\circ} \mathrm{C}$ prior to being loaded onto an $8 \%$ polyacrylamide $/ 7 \mathrm{M}$ urea/ $1 \times$ TBE ( $89 \mathrm{mM}$ Tris, $89 \mathrm{~mm}$ boric acid, $2.5 \mathrm{mM} \mathrm{Na}_{2}$ EDTA) gel that had been prenun for $30 \mathrm{~min}$ at $200 \mathrm{~V}$. Samples were electrophoresed for approximately $2.5 \mathrm{hr}$ at $200 \mathrm{~V}$, and the gel was soaked in $\mathrm{H}_{2} \mathrm{O}$ for 15-20 min and dried prior to autoradiography.

\section{Quantitation}

Incorporation of radioactivity into $\mathrm{VA}_{\mathrm{I}}$ RNA was quantitated by the excision of the relevant slices of the dried gels followed by counting in scintillation fluid (Liquiscint; National Diagnostics). Slices of equal area from the region of the gels immediately above and below the $\mathrm{VA}_{\mathrm{I}}$ transcript were also excised, and the averages of the counts of these slices were subtracted from the specific transcript incorporation to correct for background radioactivity. This background was a very small number compared to the incorporation of ${ }^{32} \mathrm{P}$ into $\mathrm{VA}_{\mathrm{I}} \mathrm{RNA}$ under multipleround transcription conditions, but it typically represented $20-50 \%$ of the apparent radioactivity incorporated under single-round conditions. No attempt was made to correct for the quenching effect of polyacrylamide; moreover, as noted in Results, we noticed substantial variation in the amount of radioactivity incorporated with the age of the $\left[\alpha^{-32}\right]$ GTP. Therefore, our estimates of the number of active complexes should be considered approximate. Nonetheless, direct relative comparisons (as in Fig. 8) can be made.

\section{Acknowledgments}

We thank the members of the Roeder laboratory, in particular Shona Murphy and Beth Moorefield, for many helpful discussions, Warren Hoeffler for the gift of some of the phosphocellulose step fractions used, and Virginia Kozler for expert assistance with tissue culture. This work was supported by Public Health Service grant CA-42567 from the National Institutes of Health (NIH) to R.G.R. and by general support from the Pew Charitable Trusts to The Rockefeller University. R.K. was a recipient of a graduate fellowship from the National Science Foundation and was also supported by NIH grant AI-07233. 


\section{References}

Babiss, L.E. 1989. The cellular transcription factor E2f requires viral E1A and E4 gene products for increased DNA-binding activity and functions to stimulate adenovirus E2A gene expression. J. Virol. 63: 2709-2717.

Bagchi, S., P. Raychaudhuri, and J.R. Nevins. 1989. Phosphorylation-dependent activation of the adenovirus-inducible E2F transcription factor in a cell-free system. Proc. Natl. Acad. Sci. 86: 4352-4356.

Baker, R.E. and B.D. Hall. 1984. Structural features of yeast tRNA genes which affect transcription factor binding. EMBO I. 3: 2793-2800.

Berk, A.J. 1986. Adenovirus promoters and ElA transactivation. Annu. Rev. Genet. 20: 45-79.

Bieker, J.J., P.L. Martin, and R.G. Roeder. 1985. Formation of a rate-limiting intermediate in 5S RNA gene transcription. Cell 40: 119-127.

Bieker, J.J. and R.G. Roeder. 1986. Characterization of the nucleotide requirement for elimination of the rate-limiting step in 5S RNA gene transcription. I. Biol. Chem. 261: 9732-9738

Bitter, G.A. 1983. Purification of DNA-dependent RNA polymerase II from Saccharomyces cerevisiae. Anal. Biochem. 128: 294-301.

Bogenhagen, D.F., W.M. Wormington, and D.D. Brown. 1982. Stable transcription complexes of Xenopus 5S RNA genes: a means to maintain the differentiated state. Cell 28: 413421.

Bradford, M.M. 1976. A rapid and sensitive method for the quantitation of microgram quantities of protein utilizing the principle of protein-dye binding. Anal. Biochem. 72: 248254.

Bunick, D., R. Zandomeni, S. Ackerman, and R. Weinmann. 1982. Mechanism of RNA polymerase II-specific initiation of transcription in vitro: ATP requirement and uncapped runoff transcripts. Cell 29: 877-886.

Buratowski, S., S. Hahn, L. Guarente, and P.A. Sharp. 1989. Five intermediate complexes in transcription initiation by RNA polymerase II. Cell 56: 549-561.

Carey, M.F., S.P. Gerrard, and N.R. Cozzarelli. 1986. Analysis of RNA polymerase III transcription complexes by gel filtration. J. Biol. Chem. 261: 4309-4317.

Ciliberto, G., L. Castagnoli, and R. Cortese. 1983. Transcription by RNA polymerase III. Curr. Top. Dev. Biol. 18: 59-88.

Cromlish, J.A. and R.G. Roeder. 1989. Human transcription factor IIIC (TFIIIC). Purification, polypeptide structure, and the involvement of thiol groups in specific DNA binding. $I$. Biol. Chem. 264: 18100-18109.

Dean, N. and A.J. Berk. 1987. Separation of TFIIIC into two functional components by sequence specific DNA affinity chromatography. Nucleic Acids Res. 15: 9895-9907.

Dignam, J.D., R.M. Lebovitz, and R.G. Roeder. 1983. Accurate transcription initiation by RNA polymerase II in a soluble extract from isolated mammalian nuclei. Nucleic Acids Res. 11: $1475-1489$.

Engelke, D.R., S.Y. Ng, B.S. Shastry, and R.G. Roeder. 1980. Specific interaction of a purified transcription factor with an internal control region of 5S RNA genes. Cell 19: 717-728.

Fuhrman, S.A., D.R. Engelke, and E.P. Geiduschek. 1984. HeLa cell RNA polymerase III transcription factors. Functional characterization of a fraction identified by its activity in a second template rescue assay. J. Biol. Chem. 259: 19341943.

Geiduschek, E.P. and G.P. Tocchini-Valentini. 1988. Transcription by RNA polymerase III. Annu. Rev. Biochem. 57: 873-
914.

Ginsberg, A.M., B.O. King, and R.G. Roeder. 1984. Xenopus 5S gene transcription factor, TFIIIA: characterization of a cDNA clone and measurement of RNA levels throughout development. Cell 39: 479-489.

Gottesfeld, J. and L.S. Bloomer. 1982. Assembly of transcriptionally active 5S RNA gene chromatin in vitro. Cell 28: $781-791$

Grummt, I. 1981. Specific transcription of mouse ribosomal DNA in a cell-free system that mimics control in vivo. Proc. Natl. Acad. Sci. 78: 727-731.

Hardy, S., D.A. Engel, and T. Shenk. 1989. An adenovirus early region 4 gene product is required for induction of the infection-specific form of cellular E2F activity. Genes Dev. 3: $1062-1074$

Hawley, D.K. and R.G. Roeder. 1985. Separation and partial characterization of three functional steps in transcription initiation by human RNA polymerase II. $J$. Biol. Chem. 260: $8163-8172$.

. 1987. Functional steps in initiation and reinitiation from the major late promoter in a HeLa nuclear extract. $I$. Biol. Chem. 262: 3452-3461.

Hoeffler, W.K. and R.G. Roeder. 1985. Enhancement of RNA polymerase III transcription by the ElA gene product of adenovirus. Cell 41: 955-963.

Hoeffler, W.K., R. Kovelman, and R.G. Roeder. 1988. Activation of transcription factor IIIC by the adenovirus E1A protein. Cell 53: 907-920.

Horikoshi, M., M.F. Carey, H. Kakidani, and R.G. Roeder. 1988a. Mechanism of action of a yeast activator: direct effect of GAL4 derivatives on mammalian TFIID-promoter interactions. Cell 54: 665-669.

Horikoshi, M., T. Hai, Y.S. Lin, M.R. Green, and R.G. Roeder. 1988b. Transcription factor ATF interacts with the TATA factor to facilitate establishment of a preinitiation complex. Cell 54: 1033-1042.

Huang, M.-M. and P. Hearing. 1989. The adenovirus early region 4 open reading frame $6 / 7$ protein regulates the DNA binding activity of the cellular transcription factor, E2F, through a direct complex. Genes Dev. 3: 1699-1710.

Kassavetis, G.A., D.L. Riggs, R. Negri, L.H. Nguyen, and E.P. Geiduschek. 1989. Transcription factor IIIB generates extended DNA interactions in RNA polymerase III transcription complexes on tRNA genes. Mol. Cell. Biol. 9: 25512566.

Kato, H., M. Nagamine, R. Kominami, and M. Muramatsu. 1986. Formation of the transcription initiation complex on mammalian rDNA. Mol. Cell. Biol. 6: 3418-3427.

Klekamp, M.S. and P.A. Weil. 1986a. Partial purification and characterization of the Saccharomyces cerevisiae transcription factor TFIIIB. J. Biol. Chem. 261: 2819-2827.

Klekamp, M.S. and P.A. Weil. 1986b. Yeast class III gene transcription factors and homologous RNA polymerase III form ternary transcription complexes stable to disruption by $\mathrm{N}$ lauroyl-sarcosine (sarcosyl). Arch. Biochem. Biophys. 246: $783-800$

Kovelman, R., W.K. Hoeffler, and R.G. Roeder. 1989. Characterization of two forms of TFIIIC regulated by the E1A protein. In DNA-protein interactions in transcription (ed. J.D. Gralla), pp. 151-160. Alan R. Liss, New York.

Kovesdi, I., R. Reichel, and J.R. Nevins. 1986a. Identification of a cellular transcription factor involved in E1A trans-activation. Cell 45: 219-228.

Kovesdi, I., R. Reichel, and J.R. Nevins. 1986b. ElA transcription induction: enhanced binding of a factor to upstream promoter sequences. Science 231: 719-722. 
Lassar, A.B., P.L. Martin, and R.G. Roeder. 1983. Transcription of class III genes: formation of preinitiation complexes. Science 222: $740-748$.

Lee, K.A. and M.R. Green. 1987. A cellular transcription factor $\mathrm{E} 4 \mathrm{~F} 1$ interacts with an Ela-inducible enhancer and mediates constitutive enhancer function in vitro. $E M B O$ I. 6: 13451353.

Maniatis, T., S. Goodbourn, and J.A. Fischer. 1987. Regulation of inducible and tissue-specific gene expression. Science 236: $1237-1245$.

McClure, W.R. 1985. Mechanism and control of transcription initiation in prokaryotes. Annu. Rev. Biochem. 54: 171204.

$\mathrm{Ng}$, S.Y., C.S. Parker, and R.G. Roeder. 1979. Transcription of cloned Xenopus 5S RNA genes by X. laevis polymerase III in reconstituted systems. Proc. Natl. Acad. Sci. 76: 136-140.

Ptashne, M. 1988. How eukaryotic transcriptional activators work. Nature 335: 683-689.

Raychaudhuri, P., R. Rooney, and J.R. Nevins. 1987. Identification of an E1A-inducible cellular factor that interacts with regulatory sequences within the adenovirus E4 promoter. $E M B O$ J. 6: 4073-4081.

Raychaudhuri, P., S. Bagchi, and J.R. Nevins. 1989. DNAbinding activity of the adenovirus-induced E4F transcription factor is regulated by phosphorylation. Genes Dev. 3: 620627.

Reichel, R., S.D. Neill, I. Kovesdi, M.C. Simon, P. Raychaudhuri, and J.R. Nevins. 1989. The adenovirus E4 gene, in addition to the ElA gene, is important for trans-activation of E2 transcription and for E2F activation. J. Virol. 63: 36433650 .

Sawadogo, M. and R.G. Roeder. 1984. Energy requirement for specific transcription initiation by the human RNA polymerase II system. J. Biol. Chem. 259: $5321-5326$.

Segall, J., T. Matsui, and R.G. Roeder. 1980. Multiple factors are required for the accurate transcription of purified genes by RNA polymerase III. $J$. Biol. Chem. 255: 11986-11991.

Setzer, D.R. and D.D. Brown. 1985. Formation and stability of the 5S RNA transcription complex. J. Biol. Chem. 260: 2483-2492.

Shastry, B.S., S.Y. Ng, and R.G. Roeder. 1982. Multiple factors involved in the transcription of class III genes in Xenopus laevis. J. Biol. Chem. 257: 12979-12986.

Simon, M.C., T.M. Fisch, B.J. Benecke, J.R. Nevins, and N. Heintz. 1988. Definition of multiple, functionally distinct TATA elements, one of which is a target in the hsp70 promoter for E1A regulation. Cell 52: 723-729.

Sklar, V.E.F. and R.G. Roeder. 1976. Purification and subunit structure of deoxyribonucleic acid-dependent ribonucleic acid polymerase III from the mouse plasmacytoma, MOPC 315. J. Biol. Chem. 251: 1064-1073.

Söderlund, H., U. Pettersson, B. Vennstrom, L. Philipson, and M.B. Mathews. 1976. A new species of virus-coded low molecular weight RNA from cells infected with adenovirus type 2. Cell 7: 585-593.

Toohey, M.G. and K.A. Jones. 1989. In vitro formation of short RNA polymerase II transcripts that terminate within the HIV-1 and HIV-2 promoter-proximal downstream regions. Genes Dev. 3: 265-282.

Van Dyke, M.W., R.G. Roeder, and M. Sawadogo. 1988. Physical analysis of transcription preinitiation complex assembly on a class II gene promoter. Science 241: 13351338.

Van Dyke, M.W., M. Sawadogo, and R.G. Roeder. 1989. Stability of transcription complexes on class II genes. Mol. Cell. Biol. 9: 342-344. von Hippel, P.H., D.G. Bear, W.D. Morgan, and J.A. McSwiggen. 1984. Protein-nucleic acid interactions in transcription: a molecular analysis. Annu. Rev. Biochem. 53: 389-446.

Waldschmidt, R., D. Jahn, and K.H. Seifart. 1988. Purification of transcription factor IIIB from HeLa cells. J. Biol. Chem. 263: $13350-13356$.

Weil, P.A., D.S. Luse, J. Segall, and R.G. Roeder. 1979. Selective and accurate initiation of transcription of eukaryotic genes by RNA polymerase III in systems reconstituted with purified DNA templates. Cell 18: 469-484.

Williams, J.F. 1970. Enhancement of adenovirus plaque formation on HeLa cells by magnesium chloride. J. Gen. Virol. 9: 251-255.

Wingender, E., D. Jahn, and K.H. Seifart. 1986. Association of RNA polymerase III with transcription factors in the absence of DNA. J. Biol. Chem. 261: 1409-1413.

Workman, J.L., S.M. Abmayr, W.A. Cromlish, and R.G. Roeder. 1988. Transcriptional regulation by the immediate early protein of pseudorabies virus during in vitro nucleosome assembly. Cell 55: 211-219.

Workman, J.L. and R.G. Roeder. 1987. Binding of transcription factor TFIID to the major late promoter during in vitro nucleosome assembly potentiates subsequent initiation by RNA polymerase II. Cell 51: 613-622.

Wu, L., D.S. Rosser, M.C. Schmidt, and A. Berk. 1987. A TATA box implicated in ElA transcriptional activation of a simple adenovirus 2 promoter. Nature 326: $512-515$.

Yoshinaga, S., N. Dean, M. Han, and A.J. Berk. 1986. Adenovirus stimulation of transcription by RNA polymerase III: evidence for an ElA-dependent increase in transcription factor IIIC concentration. EMBO I. 5: 343-354.

Yoshinaga, S.K., P.A. Boulanger, and A.J. Berk. 1987. Resolution of human transcription factor TFIIIC into two functional components. Proc. Natl. Acad. Sci. 84: 3585-3589.

Yoshinaga, S.K., N.D. L'Etoile, and A.J. Berk. 1989. Purification and characterization of transcription factor IIIC2. J. Biol. Chem. 264: 10726-10731. 


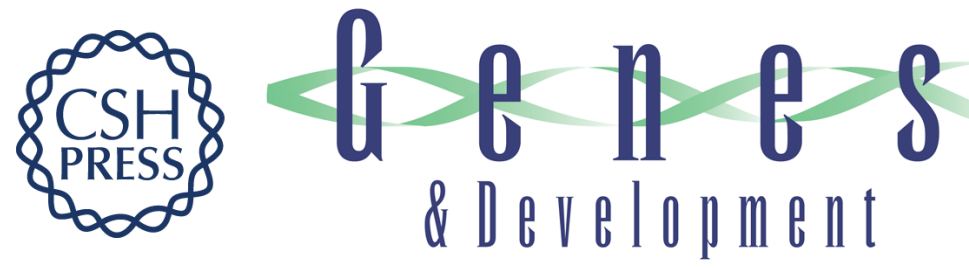

\section{Sarkosyl defines three intermediate steps in transcription initiation by RNA polymerase III: application to stimulation of transcription by} E1A.

R Kovelman and R G Roeder

Genes Dev. 1990, 4:

Access the most recent version at doi:10.1101/gad.4.4.646

References This article cites 66 articles, 32 of which can be accessed free at: http://genesdev.cshlp.org/content/4/4/646.full.html\#ref-list-1

License

Email Alerting Receive free email alerts when new articles cite this article - sign up in the box at the top Service right corner of the article or click here.

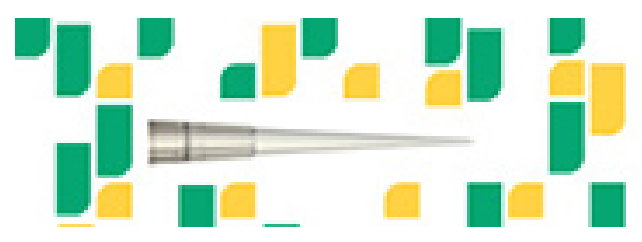

Focused on your science. 